\title{
LXI. On an improvement in the form of spectacle glasses
}

\author{
Wm. Hyde Wollaston M.D.F.R.S.
}

To cite this article: Wm. Hyde Wollaston M.D.F.R.S. (1804) LXI. On an improvement in the form of spectacle glasses, Philosophical Magazine Series 1, 17:68, 327-329, DOI: $10.1080 / 14786440408676428$

To link to this article: http://dx.doi.org/10.1080/14786440408676428

册 Published online: 18 May 2009.

Submit your article to this journal $\pi$

Џ Article views: 3

Q View related articles 5 
The muriatic acid becomes very strongly oxygenated when dissolved in hyperoxygenated sulphate of iron, which thereby acquires a yellowish colour.

The hyperoxygenation of iron increases its affinity for acids in such a manner that callico-printers make no use of an acetic solution of hyperoxygenated oxide of iron, as it does not readily give up its acid by drying.

LXI. On an Improvement in the Form of Spectacle Glasses. By WM. Hyde Wollaston, M.D.F.R.S.*

$I_{\text {T must have been remarked by persons who make use of }}$ spectacles, especially those who require glasses of short focal distance, that objects seen through them appear distinct only when viewed through the central parts of the glasses; that, when the direction of the sight E O, Fig. 1. (Plate IX.) is considerably inclined to the surfaces, objects appear distorted, and that this defect is greater in proportion to the greater obliquity of that line.

It is on this account that opticians have lately made and recommended spectacle glasses of less diameter than those formerly in use, thinking that the extreme parts of the field of vision, which from indistinctness were of little use, might be spared without much inconvenience. But this alteration in the size of the glasses could hardly claim the merit of an improvement, since for one defect it only substituted another scarcely less objectionable.

It seems indeed rather extraordinary that during five centuries which have elapsed since the invention of spectacles, neither theory nor accident should have produced any considerable variation from their original construction.

It was indeed conceived by Huygens $t$, that the glasses, instead of being equally curved on both sides, as is customary, should have the curvatures of their opposite surfaces in the proportion of 6 to 1 , because he had demonstrated that such a form was best suited to the object-glasses of telescopes.

Dr. Smith also, in his Treatise on Optics (p. 258.), repeats this opinion of Huygens in the following cursory manner: "And consequently this figure of a glass is the

* Communicated by the author.

t Dioptr. Prop. 28. 


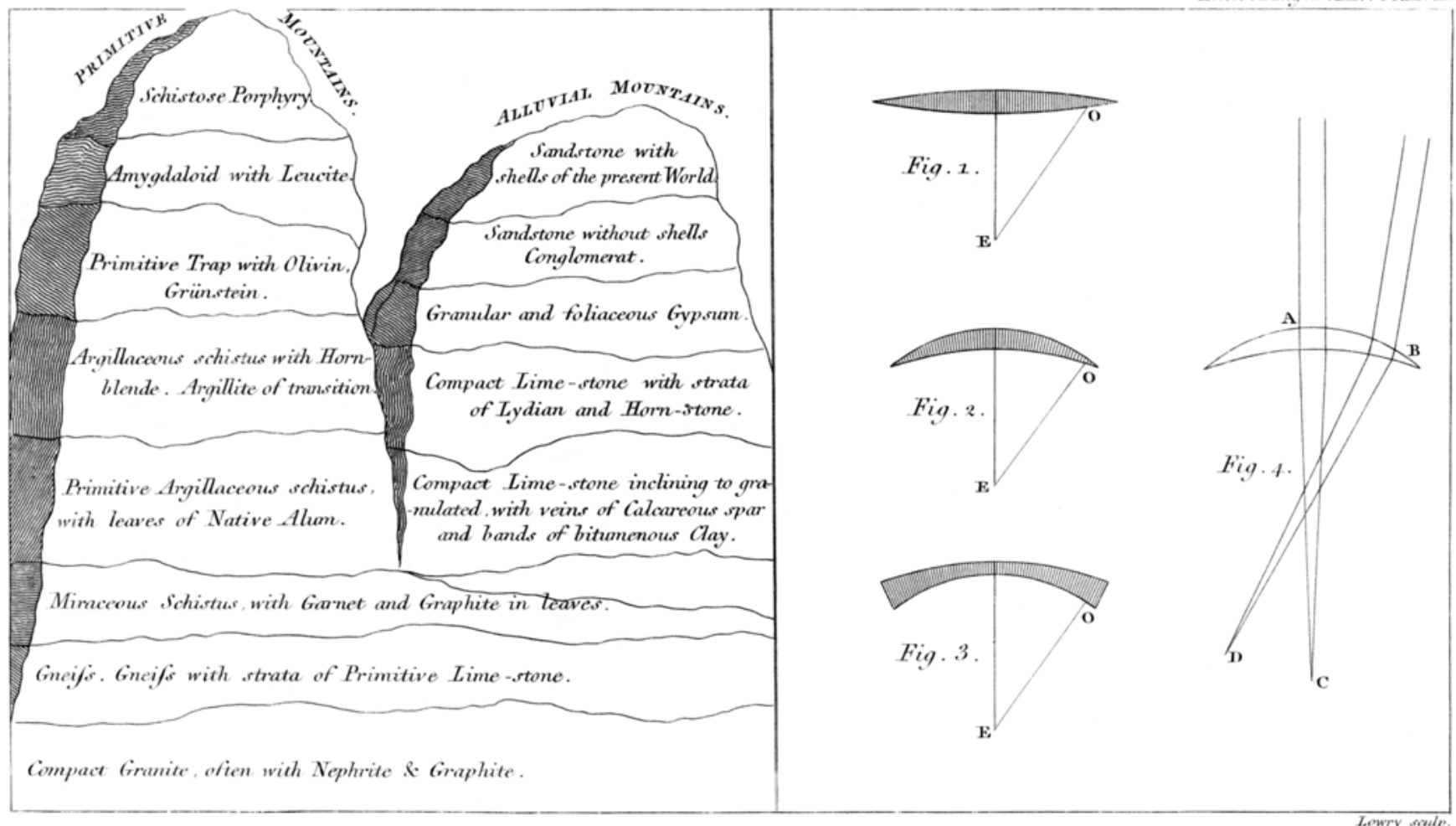




\section{Improvement in the Form of Spectacle Glasses.}

best for spectacles, as the double concave of like figure is the best to help short-sighted persons."

But although it may be very true that such a form of glass was best calculated for the object-glass of a telescope, previous to the celebrated discovery of the achromatic object-glass by the late Mr. Dollond; yet, whatever advantages might at any time be expected from the telescopic object-glass so shaped, these wcre not to be obtained by a similar construction in spectacles, as may easily be seen by considering the different uses of the respective instruments.

In a telescope, in the first place, our view is necessarily confined to a very small distance on each side of the axis : and secondly, every part of the object-glass contributes to the distinctness of any object riewed.

It is under these circunstances alone that the proportion of the curvatures above mentioned might be proper for a single object-glass, as being capable of collecting into the same focus the rays that fall on every part of it parallel to the axis.

By spectacles, on the contrary, objects are to be viewed if possible in every direction in which they might be seen by the naked eye, which is ofien far removed from the centres of the glasses; consequently, a construction that is calculated to represent correctly central objcets alone cannot be the most advantageous.

In these also the portion of the glass employed at once is scarcely larger than the pupil of the eye; so that any endeavour to procure the concurrence of all parts of a glass in any one effect is evidently superfluous, and may also be shown to be prejudicial.

It is therefore proposed to remedy the imperfections observable in the spectacle glasses hitherto generally used upon a principle suggested by this latter consideration, which presents an opportunity, by a different construction, of rendering objects in all directions distinct.

The alteration requisite for this purpose is extremely simfle, and easily intelligible. Supposing an eye to be placed in the centre of any hollow globe of glass, it is plain that objects would then be scen perpendicularly through its surface in every direction. Consequently, the more nearly any spectacle glass can be made to surround the eye, in the manner of a globular surface, the more nearly will every part of it be at right angles to the line of sight, the more uniform will be the power of its different parts, and the 
On the Strengths and Values of Spirituous Liquors. 329 more completely will the indistinctness of lateral objects be avoided*.

According to this principle all spectacle glasses should be convex on their exterior surface, and concave within. The section of those for long-sighted persons will assume the form of a meniscus or crescent, Fig. 2. and those adapted for short sight will have their principal curvature on the concave side, Fig. 3.

It is only necessary to add, that the advantage of this improvement in the form of spectacle glasses has been confirmed by a sufficient number of experiments on different persons, and that those in particular, who are very long, or very short sighted, are much benefited by them.

The most advantageous proportions of carvature for obtaining the different focal lengths, now generally distinguished by certain numbers, have also been duly considered, and the manufacture of spectacles on this construction has been undertaken by Messrs. P. and J. Dollond, to whom the exclusive sale of them is secured by patent, and whose well-known skill in the construction of optical instruments ensures to this improvement every advantage of correct execution.

The opportunity afforded by these glasses of looking routnd at various objects, it is thought may not improperly be expressed by the name of Periscopic Spectacles.

LXII. Of the general Relation letween the Specific Gravtties and the Strengths and Values of Spirituous Liquors, and the Circumstances by which the former are influenced.

[Concluded from p. 210.]

Problems and Rules for the Adaptation of Mr. Gilprin's Tables to the present Standard.

§ 31. Problem I.-The specific gravity of a liquor at any given temperature being given, to find that which it possesses at any other temperature.

* To mathematicians it will be exident that any ray which does not pass through the centre of a lens cannot be at right angles to both surfuces; but they will also perceive, thas when any small oblique pencil makes cqual angles with the two surfaces of a thin lens, the inclination of it to each is so small, that its focal length $B$ D, Fig 4. will not senvitly differ from $A C$, that of a central pencil.

Practical 